\title{
Evaluating the Platelet Distribution Width-to-Plateletcrit Ratio as a Prognostic Marker for Patients With Breast Cancer
}

\author{
HIDEYA TAKEUCHI, DAIKI NODA, MIYUKI ABE, KENTARO ANAMI, \\ MICHIYO MIYAWAKI, ATSUSHI OSOEGAWA and KENJI SUGIO \\ Department of Thoracic and Breast Surgery, Oita University Faculty of Medicine, Oita, Japan
}

\begin{abstract}
Aim: This study aimed to evaluate plateletcrit (PCT) and platelet distribution width-to-PCT ratio (PDW/PCT) as potential prognostic biomarkers in patients with breast cancer. Patients and Methods: Information of 337 patients was retrospectively reviewed. The Cox regression proportional hazards model was used to evaluate the prognostic value of PCT and PDW/PCT compared to the platelet distribution width-to-platelet count ratio $(P D W / P)$ and red cell distribution width-to-platelet count ratio $(R D W / P)$. Results: Large tumor size $(p<0.01)$, lymph node involvement, and increased $P D W / P$, $R D W / P$, and PDW/PCT $(p<0.05)$ were significantly associated with inferior disease-free survival (DFS) according to the univariate analysis. The multivariate analysis showed that large tumor size $(p<0.01)$ and increased PDW/PCT $(p<0.05)$ were significant prognostic factors for poor DFS. Conclusion: To our knowledge, this is the first report to show that PDW/PCT is a significant prognostic factor for patients with breast cancer. Therefore, it might be an attractive biomarker providing additional prognostic information for these patients.
\end{abstract}

Breast cancer represents the most common type of cancer in females in Japan and worldwide $(1,2)$. Although substantial advancements have been made in its diagnosis and treatment in past decades, the trend of increased morbidity and mortality rates is predicted to continue until 2025 in Japan $(1,3,4)$. Therefore, it is critical to identify biomarkers which allow more reliable predictions of prognosis. Various scoring systems have been developed to predict mortality. Although the tumor, node and metastasis (TNM) staging is the traditional prognostic indicator

This article is freely accessible online.

Correspondence to: Hideya Takeuchi, Department of Thoracic and Breast Surgery, Oita University Faculty of Medicine, 1-1 Idaigaoka, Hasama-machi, Yufu, Oita 879-5593, Japan. Tel: +81 975865854, Fax: +81975866449, e-mail: takeuchi@oita-u.ac.jp

Key Words: Breast cancer, platelet distribution width, plateletcrit, prognostic factor. and is widely used, this method presents heterogeneous clinical outcomes for the same staging, suggesting a lack of accuracy and adequacy (5). Expensive molecular diagnostic devices, such as Oncotype DX and Mammaprint, might be useful for providing prognostic information and aiding in decision-making for clinical therapy. However, these are not available in Japan because they are not covered by the national insurance scheme. Therefore, it is crucial and beneficial to identify simple, costefficient, and sensitive biomarkers that can be measured by common routine automated blood count analyzers.

Growing evidence has revealed that activated platelets have a vital role in cancer progression because of their release of cytokines, chemokines, and adhesion receptors $(6,7)$. We have already reported that platelet-related markers, such as the platelet-to-lymphocyte ratio (PLR), are novel prognostic factors for patients with breast cancer $(8,9)$. The platelet distribution width (PDW), which reflects the variance in platelet size, is considered a marker of platelet function and activation (10). Higher PDW levels have been demonstrated to be associated with increased morbidity and mortality among patients with coronary disease (11) and cancer (12). We have already established that the PDW-to-platelet count ratio (PDW/P) is a significant prognostic factor for patients with breast cancer (13). The plateletcrit (PCT), which is calculated from the platelet count and mean platelet volume (MPV), reflects platelet activity and the percentage of platelets in the blood (14). An association of PCT with severity in certain inflammatory diseases and vascular diseases has been demonstrated $(15,16)$. Recently, an increased PCT level has been found to be associated with unfavorable prognosis for patients with colorectal and endometrial cancer $(17,18)$.

The influence of PCT on the prognosis of patients with breast cancer has not been defined. Hence, in the present study, we investigated the prognostic roles of PCT and the PDW to PCT ratio (PDW/PCT) in disease-free survival (DFS) rates of patients with breast cancer and compared the PDW/P and red cell distribution-to-platelet ratio (RDW/P), which have been already recognised as significant prognostic factors (13, 19). To the best of our knowledge, this is the first report of the prognostic value of PCT in patients with breast cancer. 
Table I. Basic characteristics of the study patients.

\begin{tabular}{llr}
\hline Variable & & No. $(\%)$ \\
\hline Age, years & $<50$ & $46(14)$ \\
Tumor size, mm & $\geq 50$ & $291(86)$ \\
& $<20$ & $225(67)$ \\
ER & $\geq 20$ & $112(33)$ \\
& - & $78(23)$ \\
Nuclear grade & + & $259(77)$ \\
& 1,2 & $268(80)$ \\
HER2 & 3 & $69(20)$ \\
& - & $278(82)$ \\
LN involvement & + & $59(18)$ \\
& - & $273(81)$ \\
PgR & + & $64(19)$ \\
& - & $125(37)$ \\
PCT & + & $212(63)$ \\
PDW/P & $<0.22$ & $148(44)$ \\
& $\geq 0.22$ & $189(56)$ \\
RDW/P & $<0.587$ & $225(67)$ \\
& $\geq 0.587$ & $112(33)$ \\
PDW/PCT & $<0.706$ & $259(77)$ \\
& $\geq 0.706$ & $78(23)$ \\
& $<59.0$ & $226(67)$ \\
& $\geq 59.0$ & $111(33)$ \\
\hline
\end{tabular}

ER: Estrogen receptor; HER2: human epidermal growth factor receptor 2; LN: lymph node; PgR: progesterone receptor; PCT: plateletcrit; PDW: platelet distribution width; RDW: red cell distribution width; P: platelet count.

\section{Patients and Methods}

Study population and design. We retrospectively analysed 482 patients with histologically confirmed breast cancer who underwent surgery at the Department of Thoracic and Breast Surgery, Oita University Faculty of Medicine between April 2006 and May 2019. One hundred and forty-five patients were excluded from our analysis due to the presence of carcinoma in situ in 47, bilateral breast carcinoma in 15 , distant metastases at initial presentation in 13, preoperative chemotherapy in 22 , liver cirrhosis in six, synchronous malignant disease in 10 , chronic renal failure in six, collagen disease in two, insufficient laboratory data in 18 , and six males with breast cancer. Finally, 337 patients with breast cancer were eligible for this study. We administered adjuvant therapy according to the St. Gallen recommendations (20), as previously described in detail $(13,19)$.

Pathological characteristics. As described previously (13, 19), pathological data were reviewed to determine the tumor size, nuclear grade, lymph node involvement, hormone receptor status and human epidermal growth factor receptor 2 (HER2) status. Estrogen and progesterone receptor statuses were evaluated by immunohistochemistry (IHC). Tumors with hormone receptor expression scores above zero were defined as positive. HER2 status was assessed via IHC or fluorescence in situ hybridisation and was considered positive upon obtaining either an IHC score of 3 or an HER2 signal at least 2.2-fold stronger relative to the CEP-17 signal in tumor cells (21).
Table II. Receiver operating characteristics analyses of platelet volumetric indices in patients with breast cancer.

\begin{tabular}{lcccc}
\hline Variable & $\begin{array}{c}\text { Cut-off } \\
\text { value }\end{array}$ & $\begin{array}{c}\text { AUC } \\
(95 \% \mathrm{CI})\end{array}$ & Specificity & Sensitivity \\
\hline $\mathrm{PCT}$ & 0.22 & $0.625(0.51-0.73)$ & 0.487 & 0.759 \\
$\mathrm{PDW} / \mathrm{P}$ & 0.587 & $0.656(0.55-0.75)$ & 0.692 & 0.586 \\
$\mathrm{RDW} / \mathrm{P}$ & 0.706 & $0.549(0.43-0.66)$ & 0.786 & 0.414 \\
$\mathrm{PDW} / \mathrm{PCT}$ & 59.0 & $0.69(0.58-0.79)$ & 0.705 & 0.69 \\
\hline
\end{tabular}

PCT: Plateletcrit; PDW: PDW/P: platelet distribution width-to-platelet count ratio; RDW/P: red cell distribution width-to-platelet count ratio; PDW/PCT: platelet distribution width-to-plateletcrit ratio; AUC: area under the receiver operating characteristics curve; CI: confidence interval.

Definitions. PDW/P and RDP/P were calculated as PDW and RDW divided by the platelet count $\left(10^{4} \mathrm{ml} / \mu \mathrm{l}\right)$, respectively. PDW/PCT was calculated as the PDW divided by the PCT. The ideal cut-off value was determined by receiver-operating characteristic (ROC) analysis.

Statistical analysis. As described previously $(13,19)$, all statistical analyses were performed using EZR (Saitama Medical Center, Jichi Medical University, Saitama, Japan), which is a graphical user interface for $\mathrm{R}$ (The $\mathrm{R}$ Foundation for Statistical Computing, Vienna, Austria) (22). A value of $p<0.05$ was considered significant.

The primary endpoint of the study was DFS, which was defined as the interval from the date of surgery to the first observation of disease recurrence or last follow-up. Parameters are expressed as means \pm standard deviation. The between-group differences were determined using Student's $t$-test.

The survival curve was plotted using the Kaplan-Meier method. A Cox proportional hazards model was applied to identify any independent variables associated with DFS. Hazard ratios (HRs) estimated using Cox analysis were reported as relative risks with their corresponding 95\% confidence intervals (CIs).

Data collection and ethics compliance. Blood samples were obtained via peripheral venous puncture prior to surgery. PCIs were quantified routinely with an automatic nephelometer (XN-9000; Sysmex Corporation, Kobe, Japan).

This study was approved by the institutional ethics review board (the Clinical Research Board of Oita University; institutional ID: 1770). All data were anonymised and compiled. The study plan and choice to freely decline participation were announced through the hospital bulletin at the Oita University Faculty of Medicine. Patients were recognised to have consented to the study if they did not refuse participation.

\section{Results}

Patient characteristics. The demographic, clinical and laboratory data of the analysed patients are summarised in Table I. The median age was 64.1 years (range $=31-92$ years). ROC analysis can be considered an indicator of overall accuracy and an index of diagnostic performance. The ROC 
Takeuchi et al: Platelet Distribution Width-to-Plateletcrit Ratio as a Breast Cancer Prognostic Marker

Table III. Association between platelet volumetric indices and clinicopathological factors in patients with breast cancer.

\begin{tabular}{|c|c|c|c|c|c|c|c|c|c|c|c|c|c|}
\hline \multirow[b]{2}{*}{ Variable } & & \multicolumn{3}{|c|}{ PCT } & \multicolumn{3}{|c|}{$\mathrm{PDW} / \mathrm{P}$} & \multicolumn{3}{|c|}{ RDW/P } & \multicolumn{3}{|c|}{ PDW/PCT } \\
\hline & & Mean & SD & $p$-Value & Mean & SD & $p$-Value & Mean & SD & $p$-Value & Mean & SD & $p$-Value \\
\hline \multirow[t]{2}{*}{ Age, years } & $<50$ & 0.25 & 0.067 & 0.0006 & 0.486 & 0.153 & 0.025 & 0.535 & 0.112 & 0.002 & 51.71 & 18.31 & 0.07 \\
\hline & $\geq 50$ & 0.22 & 0.052 & & 0.569 & 0.243 & & 0.625 & 0.197 & & 58.38 & 24.28 & \\
\hline \multirow[t]{2}{*}{ Tumor size, mm } & $<20$ & 0.225 & 0.055 & 0.56 & 0.543 & 0.215 & 0.12 & 0.612 & 0.184 & 0.88 & 55.61 & 21.51 & 0.04 \\
\hline & $\geq 20$ & 0.221 & 0.055 & & 0.585 & 0.267 & & 0.615 & 0.203 & & 61.21 & 27.14 & \\
\hline \multirow[t]{2}{*}{ ER } & - & 0.225 & 0.055 & 0.85 & 0.586 & 0.302 & 0.22 & 0.606 & 0.199 & 0.72 & 61.02 & 29.17 & 0.13 \\
\hline & + & 0.223 & 0.055 & & 0.549 & 0.21 & & 0.615 & 0.188 & & 56.40 & 21.65 & \\
\hline \multirow[t]{2}{*}{ Nuclear grade } & 1,2 & 0.225 & 0.057 & 0.49 & 0.554 & 0.23 & 0.58 & 0.611 & 0.195 & 0.72 & 57.19 & 23.51 & 0.66 \\
\hline & 3 & 0.22 & 0.048 & & 0.571 & 0.25 & & 0.62 & 0.171 & & 58.57 & 24.29 & \\
\hline \multirow[t]{2}{*}{ HER2 } & - & 0.219 & 0.054 & 0.001 & 0.574 & 0.241 & 0.0046 & 0.625 & 0.195 & 0.008 & 59.46 & 24.62 & 0.0007 \\
\hline & + & 0.245 & 0.055 & & 0.479 & 0.182 & & 0.554 & 0.156 & & 48.12 & 15.28 & \\
\hline \multirow[t]{2}{*}{$\mathrm{LN}$ involvement } & - & 0.223 & 0.053 & 0.4 & 0.552 & 0.226 & 0.43 & 0.615 & 0.194 & 0.68 & 56.66 & 21.83 & 0.195 \\
\hline & + & 0.229 & 0.064 & & 0.578 & 0.268 & & 0.604 & 0.177 & & 60.92 & 30.14 & \\
\hline \multirow[t]{2}{*}{ PgR } & - & 0.218 & 0.055 & 0.12 & 0.594 & 0.301 & 0.025 & 0.63 & 0.229 & 0.205 & 62.51 & 29.47 & 0.0025 \\
\hline & + & 0.227 & 0.055 & & 0.535 & 0.181 & & 0.603 & 0.163 & & 54.50 & 18.85 & \\
\hline
\end{tabular}

ER: Estrogen receptor; HER2: human epidermal growth factor receptor 2; LN: lymph node; PgR: progesterone receptor; PCT: plateletcrit; PDW: platelet distribution width; RDW: red cell distribution width; P: platelet count; SD: standard deviation. Bold values indicate statistical significance.

analysis defined the optimal cut-off values for DFS as 0.22 , $0.587,0.706$, and 59 for PCT, PDW/P, RDP/P, and PDW/PCT, respectively (Table II). Patients were separated into two groups based on their PCT, PDW/P, RDW/P, and PDW/PCT according to the cut-off values established by the ROC analysis.

Association between platelet volumetric indices and clinicopathological factors. Associations between PDW/PCT and clinicopathological variables are shown in Table III. The correlations of PDW/PCT with tumor size, HER2, and progesterone receptor status $(p<0.05)$ are shown in Table III.

Survival. After a median follow-up of 47 months, 29 patients $(8.7 \%)$ had experienced recurrence. The univariate analysis revealed that tumor size, lymph-node involvement, $\mathrm{PCT}, \mathrm{PDW} / \mathrm{P}, \mathrm{RDW} / \mathrm{P}$, and PDW/PCT had significant impact on DFS. Therefore, significant variables revealed by the univariate analysis were subjected to a multivariate analysis. According to the multivariate analysis, large tumor size and increased PDW/P were significantly correlated with a poor prognosis for DFS, with a hazard ratio of $5.57(95 \%$ confidence intervaI=2.41-12.87; $p<0.01)$, and $3.59(95 \%$ confidence intervaI $=1.19-10.79 ; p<0.05)$, respectively (Table IV).

The DFS rate was significantly lower in the group with high $\mathrm{PDW} / \mathrm{P}$ than in the group with low PDW/P (5-year survival: $94.9 \%$ vs. $77.2 \%, p<0.05$ ) (Figure 1).

\section{Discussion}

As far as we are aware, this study is the first to show increased PDW/PCT to be significantly associated with larger tumor size and negative estrogen receptor expression, and that it is a significant unfavorable prognostic factor for patients with breast cancer. The most significant outcome of the present study is that the impact of PDW/PCT as a prognostic factor was found to be superior to $\mathrm{PDW} / \mathrm{P}$ and $\mathrm{RDW} / \mathrm{P}$, which have already been recognised as significant prognostic factors for patients with breast cancer.

PDW, which is a specific marker of platelet activation, acts as an index of variation and heterogeneity in platelet volume (10). There is a strong linkage between cancer and inflammation. Platelet activation has an inducible role in the inflammatory process in cancerous disease by the secretion of pro-inflammatory factors, chemokines, and growth factors which can promote tumor cell growth, angiogenesis, and metastasis (23). Secretion of these factors by growing tumors accelerates heterogenic megakaryocytic maturation, resulting in the production and secretion of immature platelets of several sizes into the peripheral circulation, thus leading to an increased PDW (24). Therefore, an increased PDW has been shown to be a significant unfavorable prognostic factor for a variety of malignant diseases $(17,18)$. We already demonstrated PDW/P to be a significant prognostic factor for patients with breast cancer in a previous study (13).

PCT is a platelet index that reflects the total platelet mass per unit of volume and is associated with platelet plaque formation (15). PCT is also correlated with C- 
Table IV. Disease-free survival analyses of patients with breast cancer according to clinicopathological factors and platelet volumetric indices.

\begin{tabular}{|c|c|c|c|c|c|}
\hline \multirow[b]{2}{*}{ Variable } & & \multicolumn{2}{|c|}{ Univariate analysis } & \multicolumn{2}{|c|}{ Multivariate analysis } \\
\hline & & Hazard ratio $(95 \% \mathrm{CI})$ & $p$-Value & Hazard ratio $(95 \% \mathrm{CI})$ & $p$-Value \\
\hline Age, years & $\begin{array}{l}<50 \\
\geq 50\end{array}$ & $\begin{array}{c}1 \\
0.48(0.2-1.13)\end{array}$ & 0.09 & & \\
\hline Tumor size, mm & $\begin{array}{l}<20 \\
\geq 20\end{array}$ & $\begin{array}{c}1 \\
5.29(2.4-11.65)\end{array}$ & 0.00003 & $\begin{array}{c}1 \\
5.576(2.41-12.87)\end{array}$ & 0.00005 \\
\hline ER & $\begin{array}{l}- \\
+\end{array}$ & $\begin{array}{c}1 \\
0.99(0.42-2.34)\end{array}$ & 0.99 & & \\
\hline Nuclear grade & $\begin{array}{l}1,2 \\
3\end{array}$ & $\begin{array}{c}1 \\
1.79(0.83-3.85)\end{array}$ & 0.13 & & \\
\hline HER2 & $\begin{array}{l}- \\
+\end{array}$ & $\begin{array}{c}1 \\
0.69(0.2-2.28)\end{array}$ & 0.54 & & \\
\hline $\mathrm{LN}$ involvement & $\begin{array}{l}- \\
+\end{array}$ & $\begin{array}{c}1 \\
3.06(1.46-6.41)\end{array}$ & 0.003 & $\begin{array}{c}1 \\
1.87(0.86-4.05)\end{array}$ & 0.1 \\
\hline $\operatorname{PgR}$ & $\begin{array}{l}- \\
+\end{array}$ & $\begin{array}{c}1 \\
1.19(0.55-2.55)\end{array}$ & 0.64 & & \\
\hline PCT & $\begin{array}{l}<0.22 \\
\geq 0.22\end{array}$ & $\begin{array}{c}1 \\
0.59(0.28-1.25)\end{array}$ & 0.17 & & \\
\hline PDW/P & $\begin{array}{l}<0.587 \\
\geq 0.587\end{array}$ & $\begin{array}{c}1 \\
2.35(1.11-4.94)\end{array}$ & 0.024 & $\begin{array}{c}1 \\
0.77(0.24-2.41)\end{array}$ & 0.66 \\
\hline RDW/P & $\begin{array}{l}<0.706 \\
\geq 0.706\end{array}$ & $\begin{array}{c}1 \\
2.24(1.07-4.7)\end{array}$ & 0.032 & $\begin{array}{c}1 \\
1.7(0.66-4.36)\end{array}$ & 0.26 \\
\hline $\mathrm{PDW} / \mathrm{PCT}$ & $\begin{array}{l}<59.0 \\
\geq 59.0\end{array}$ & $\begin{array}{c}1 \\
3.63(1.64-8.03)\end{array}$ & 0.001 & $\begin{array}{c}1 \\
3.59(1.19-10.79)\end{array}$ & 0.022 \\
\hline
\end{tabular}

ER: Estrogen receptor; HER2: human epidermal growth factor receptor 2; LN: lymph node; PgR: progesterone receptor; PCT: plateletcrit; PDW: platelet distribution width; RDW: red cell distribution width; P: platelet count; SD: standard deviation. Bold values indicate statistical significance.

reactive protein in chronic inflammatory disease (25). Reports have demonstrated that PCT is a sensitive marker for disease activity in patients with Crohn's disease and is associated with the clinical outcomes of patients with myocardial infarction $(15,26)$. PCT is associated with platelet plaque formation, which includes tumor cellinduced platelet aggregation through tumor cells and platelet-related interaction, resulting in the release of platelet cytokines to tumor cells $(27,28)$. PCT was higher in patients with epithelial ovarian cancer compared to a healthy control group (29), and increased PCT was also associated with shorter survival in those with pancreatic adenocarcinoma (14).

These results showed that both PDW and PCT were indicators of the systemic inflammatory response and are associated with platelet-involved inflammation in cancer. Although the mechanisms underlying the association between an increased ratio of PDW/PCT and poor prognosis remain unclear, one may deduce that the combination of PDW and PCT measurements may be a significant prognostic factor for patients with breast cancer. However, further investigations are required to determine why a high $\mathrm{PDW} / \mathrm{PCT}$ is associated with poor prognosis for patients with breast cancer.

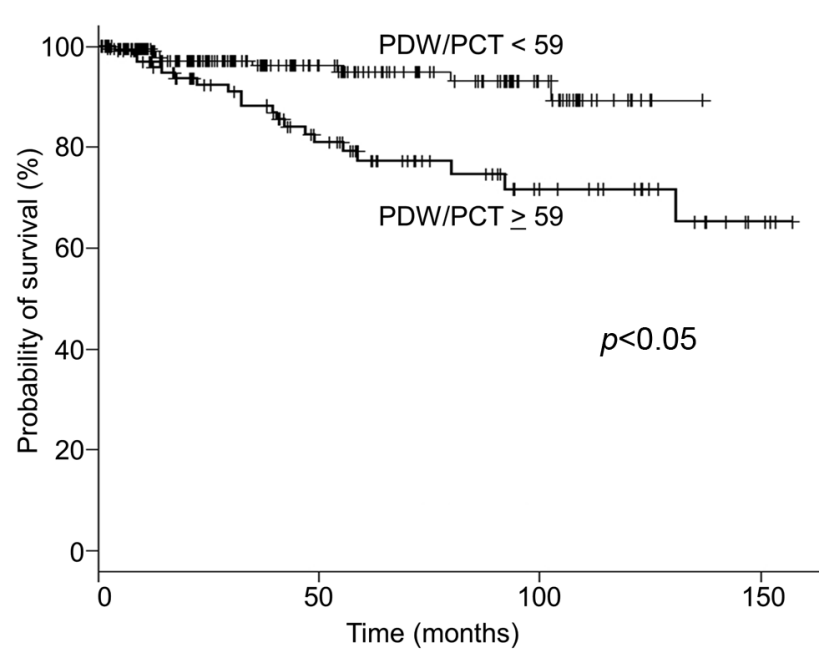

Figure 1. Kaplan-Meier analysis of disease-free survival of patients with breast cancer classified according to the platelet distribution width-to-plateletcrit (PDW/PCT) ratio.

This study had several limitations. Firstly, it had a relatively small sample size, and its single-center retrospective design may have created bias in sample selection and analysis. Secondly, differences in platelet 
indices based on ethnicity might require further investigations before the results can be applied to other ethnic groups (30). Thirdly, some unaccounted confounders, such as nutrition and comorbid disease, might have influenced the results. Despite these limitations, our study is the first to show that an increased PDW/PCT ratio may be an unfavorable marker for patients with breast cancer.

Our data indicate that an increased PDW/PCT ratio may represent a novel prognostic factor for patients with breast cancer. The evaluation of the PDW/PCT ratio using routine blood count test is highly reproducible and relatively inexpensive. However, our data are preliminary and multicentric prospective studies are necessary to verify our results.

\section{Conflicts of Interest}

The Authors have no conflicts of interest to disclose.

\section{Authors' Contributions}

H.T. and K.S. participated in manuscript preparation, data analysis and editing. H.T., D.N, and K.A. participated in data collection and data analysis. H.T., M.M. and A.O. participated in study design, data analysis, and manuscript preparation. H.T. and K.S. participated in manuscript revision. All Authors reviewed the manuscript.

\section{Acknowledgements}

The Authors would like to thank the anonymous reviewers for reading and revising the text.

\section{References}

1 Hori M, Matsuda T, Shibata A, Katanoda K, Sobue T and Nishimoto H: Cancer incidence and incidence rates in Japan in 2009: a study of 32 population-based cancer registries for the monitoring of cancer incidence in Japan (MCIJ) project. Jpn J Clin Oncol 45(9): 884-891, 2015. PMID: 26142437. DOI: 10.1093/jjco/hyv088

2 Desantis CE, Bray F, Ferlay J, Lortet-Tieulent J, Anderson BO and Jemal A: International variation in female breast cancer incidence and mortality rates. Cancer Epidemiol Biomarkers Prev 24(10): 1495-1506, 2015. PMID: 26359465. DOI: 10.1158/1055-9965.EPI-15-0535

3 Nakamura K, Okada E, Ukawa S, Hirata M, Nagai A, Yamagata Z, Kiyohara Y, Muto K, Kamatani Y, Ninomiya T, Matsuda K, Kubo M, Nakamura Y and BioBank Japan Cooperative Hospital Group: Characteristics and prognosis of Japanese female breast cancer patients. The BioBank Japan Project. J Epidemiol 27(3S): 58-64, 2017. PMID: 28202209. DOI: 10.1016/j.je.2016.12.009

4 Toyoda Y, Tabuchi T, Nakayama T, Hojo S, Yoshikawa S and Maeura Y: Past trends and future estimation of annual breast cancer incidence in Osaka, Japan. Asian Pac J Cancer Prev 17(6): 2847-2852, 2016. PMID: 27356700.

5 Kraeima J, Siesling S, Vliegen IM, Klaase JM and IJzerman MJ: Individual risk profiling for breast cancer recurrence: Towards tailored follow-up schemes. Br J Cancer 109(4): 866-871, 2013. PMID: 23860534. DOI: 10.1038/bjc.2013.401
6 Nash GF, Turner LF, Scully MF and Kakkar AK: Platelets and cancer. Lancet Oncol 3(7): 425-430, 2002. PMID: 12142172.

7 Franco AT, Corken A and Ware J: Platelets at the interface of thrombosis, inflammation, and cancer. Blood 126(5): 582-588, 2015. PMID: 26109205. DOI: 10.1182/blood-2014-08-531582

8 Takeuchi H, Fukuyama S, Kubo N, Hiroshige S, Kawanaka H, Yoshikawa Y and Yano T: The prognostic significance of the preoperative platelet-lymphocyte ratio in Japanese patients with localised breast cancer. Adv Breast Cancer Res 5: 49-57, 2016. DOI: 104236/abcr.2016.52005

9 Takeuchi H, Kawanaka H, Fukuyama S, Kubo N, Hiroshige S and Yano T: Comparison of the prognostic values of preoperative inflammation-based parameters in patients with breast cancer. PLoS One 12(5): e0177137, 2017. PMID: 28489884. DOI: 10.1371/journal.pone. 0177137

10 Vagdatli E, Gounari E, Lazaridou E, Katsibourlia E, Tsikopoulou F and Labrianou I: Platelet distribution width: a simple, practical and specific marker of activation of coagulation. Hippokratia 14: 28-32, 2010. PMID: 20411056.

11 Kern A, Gil RJ, Bojko K, Sienkierwicz E, Januszko-Gierqielewicz $\mathrm{B}$, Gorny $\mathrm{J}$ and Bil J: Platelet distribution width as the prognostic marker in coronary bifurcation treatment. Eur J Clin Invest 47(7): 524-530, 2017. PMID: 2855728. DOI: 10.1111/eci.12773

12 Zhang H, Liu L, Fu S, Liu YS, Wang C, Liu T, Liu ZP, Wang RT and Yu KJ: Higher platelet distribution width predicts poor prognosis in laryngeal cancer. Oncotarget 8(29): 48138-48144, 2017. PMID: 28624815. DOI: $10.18632 /$ oncotarget.18306

13 Takeuchi H, Abe M, Takumi Y, Hashimoto T, Kobayashi R, Osoegawa A, Miyawaki M, Okamoto $\mathrm{T}$ and Sugio K: The prognostic impact of the platelet distribution width-to-platelet count ratio in patients with breast cancer. PloS One 12(12): e0189166, 2017. PMID: 29216259. DOI: 10.1371/journal.pone.0189166

14 Wang L, Sheng L and Liu P: The independent association of platelet parameters with overall survival in pancreatic adenocarcinoma receiving intensity-modulated radiation therapy. Int J Clin Exp Med 8(11): 21215-21221, 2015. PMID: 26885057.

15 Tang J, Gao X, Zhi M, Zhou HM, Zhang M, Chen HW, Yang QF and Liang ZZ: Plateletcrit: A sensitive biomarker for evaluating disease activity in Crohn's disease with low hs-CRP. J Dig Dis 16(3): 118-24, 2015. PMID: 25565427. DOI: 10.1111/1751-2980.12225

16 Akpinar I, Sayin MR, Gursoy YC, Aktop Z, Karabag T, Kucuk E, Sen N, Aydin M, Kiran S, Buyukuyashi MC and Haznedaroglu IC: Plateletcrit and red cell distribution width are independent predictors of the slow coronary flow phenomenon. J Cardiol 63(2): 112-118, 2014. PMID: 24012331. DOI: 10.1016/j.jjcc.2013.07.010

17 Zhu X, Cao Y, Lu P, Kang Y, Lin Z, Hao Y and Song Y: Evaluation of platelet indices as diagnostic biomarkers for colorectal cancer. Sci Rep 8(1): 11814, 2018. PMID: 30087357. DOI: $10.1038 / \mathrm{s} 41598-018-29293-\mathrm{x}$.

18 Karateke A, Kaplanoglu M and Baloglu A: Relations of platelet indices with endometrial hyperplasia and endometrial cancer. Asian Pac J Cancer Prev 16(12): 4905-4908, 2015. PMID: 26163613.

19 Takeuchi H, Abe M, Takumi Y, Hashimoto T, Miyawaki M, Okamoto $\mathrm{T}$ and Sugio K: Elevated red cell distribution width to platelet count ratio predicts poor prognosis in patients with breast cancer. Sci Rep 9(1): 3033, 2019. PMID: 30816333. DOI: 10.1038/s41598-019-40024-8 
20 Curigliano G, Burstein HJ, Winer EP, Gnant M, Dubsky P, Loibl S, Colleoni M, Regan MM, Piccart-Gebhart M, Senn HJ, Thürlimann B, André F, Baselga J, Bergh J, Bonnefoi H, Brucker SY, Cardoso F, Carey L, Ciruelos E, Cuzick J, Denkert C, Di Leo A, Ejlertsen B, Francis P, Galimberti V, Garber J, Gulluoglu B, Goodwin P, Harbeck N, Hayes DF, Huang CS, Huober J, Khaled H, Jassem J, Jiang Z, Karlsson P, Morrow M, Orecchia R, Osborne KC, Pagani O, Partridge AH, Pritchard K, Ro J, Rutgers EJT, Sedlmayer F, Semiglazov V, Shao Z, Smith I, Toi M, Tutt A, Viale G, Watanabe T, Whelan TJ and Xu B: De-escalating and escalating treatments for early-stage breast cancer: The St. Gallem International Expert Consensus conference on the primary therapy of early breast cancer 2017. Ann Oncol 29(10): 2153, 2018. PMID: 29733336. DOI: 10.1093/annonc/mdx806

21 Noh H, Eomm M and Han A: Usefulness of pretreatment neutrophil to lymphocyte ratio in predicting disease-specific survival in breast cancer patients. J Breast Cancer 16(1): 55-59, 2013. PMID: 23593082. DOI: $10.4048 /$ jbc.2013.16.1.55

22 Kanda Y: Investigation of the freely available easy-to-use software "EZR" for medical statistics. Bone Marrow Transplant 48(3): 452458, 2013. PMID: 23208313. DOI: 10.1038/bmt.2012.244

23 Banks RE, Forbes MA, Kinsey SE, Stanley A, Ingham E, Walters $\mathrm{C}$ and Selby PJ: Release of the angiogenic cytokine vascular endothelial growth factor (VEGF) from platelet: Significance for VEGF measurements and cancer biology. Br J Cancer 77(6): 956-964, 1998. PMID: 9528841.

24 Leader A, Pereg D and Lishner M: Are platelet volume indices of clinical use? A Multidisciplinary review. Ann Med 44(8): 805816, 2012. PMID: 22413913. DOI: 10.3109/07853890. 2011.653391
25 Sahin F, Yazar E and Yildiz P: Prominent features of platelet count, plateletcrit, mean platelet volume and platelet distribution width in pulmonary tuberculosis. Multidiscip Respir Med 7(1): 38, 2012. PMID: 23114411. DOI: 10.1186/2049-6958-7-38

26 Gul M, Uyarel H. Akqul O, Akkaya E, Surgit O, Cakmak HA, Pusuroglu H, Yakisan T, Aslan S and Eksik A: Long-term prognostic significance of admission plateletcrit values in patients with non-ST elevation myocardial infarction. Blood Coagul Fibrinolysis 27(6): 696-701, 2016. PMID: 26820228. DOI: $10.1097 / \mathrm{MBC} .0000000000000484$

27 Mahdavi-Zafarghandi R, Shakiba B, Keramati MR and Tavakkoli M: Platelet volume indices in patients with varicocele. Clin Exp Reprod Med 41(2): 92-95, 2014. PMID: 25045634. DOI: $10.5653 /$ cerm.2014.41.2.92

28 Goubran HA, Stakiw J, Radosevic M and Bumouf T: Plateletcancer interactions. Semin Thromb Hemost 40(3): 296-305, 2014. PMID: 24590421. DOI: 10.1055/s-0034-1370767.

29 Ma X, Wang Y, Sheng H, Tian W, Qi Z, Teng F and Xue F: Prognostic significance of thrombocytosis, platelet parameters and aggregation rates in epithelial ovarian cancer. J Obstet Gynaecol Res 40(1): 178-183, 2014. PMID: 24102732. DOI: $10.1111 /$ jog. 12151

30 Segal JB and Moliterno AR: Platelet counts differ by sex, ethnicity, and age in the United States. Ann Epidemiol 16(12): 123-130, 2006. PMID: 16246584.

Received April 22, 2020

Revised May 15, 2020

Accepted May 19, 2020 